\title{
Diode Laser Lithotripsy of Urinary Calculi Using Controlled Fragmentation Techinique
}

\author{
DOI: $10.17691 / \mathrm{stm} 2019.11 .2 .15$ \\ Received August 6, 2018
}

\begin{abstract}
O.S. Streltsova, MD, DSc, Professor, E.V. Shakhov Urology Department';
E.V. Grebenkin, Resident, E.V. Shakhov Urology Department';

V.I. Bredikhin, DSc, Leading Researcher';

K.E. Yunusova, MD, PhD, Associate Professor, Department of Pathological Anatomy';

V.V. Elagin, Researcher, Institute of Experimental Oncology and Biomedical Technologies';

V.A. Kamensky, DSc, Leading Researcher ${ }^{2}$
\end{abstract}

${ }^{1}$ Privolzhsky Research Medical University, 10/1 Minin and Pozharsky Square, Nizhny Novgorod, 603005, Russia;

${ }^{2}$ Federal Research Center Institute of Applied Physics, Russian Academy of Sciences, 46 Ulyanova St., Nizhny Novgorod, 603950, Russia

One of the triggers of infectious processes developing in the kidney after contact laser lithotripsy is calculus disintegration followed by the release of bacteria and toxins from the biofilm. Prevention urgency determines the search for new mechanisms and methods of laser calculus fragmentation without scattering of fragments and microbial dissemination into the pelvicalyceal system of the kidney.

The aim of the study was to evaluate the possibilities of applying the technology of urinary calculus fragmentation with continuouswave diode lasers of different wavelengths using fiber light guides with strongly heated distal tips for controlled fragmentation and minimization of traumatic effects on the adjacent tissues.

Materials and Methods. To fragment postoperative samples of porous urinary stones $(n=58)$, we applied standard certified continuouswave diode $10 \mathrm{~W}$ lasers with fiber output to quartz light guides, their distal tips being coated with a layer of graphite microparticles in silicone varnish. The quality of stone fragmentation using lasers with wavelengths of $0.81(n=17), 0.97(n=22)$, and $1.47 \mu m(n=19)$ and identical quartz light guides were evaluated. Control of laser-induced heating of the urinary tract tissues adjacent to the stone was carried out on the model medium with a thermocouple. Simulation of intraoperative errors (short contact with the ureteral wall as the result of the fiber slipping off the stone surface) was performed on the ureteral wall took post mortem. Tissue condition was assessed using histological sections stained with hematoxylin and eosin.

Results. The average fragmentation time depended on calculus density and cross-sectional dimension and was 12-15 s. All selected stones, including those potentially infected, with X-ray density 119 to $1735 \mathrm{HU}$ were fragmented effectively both in liquid and air. Assessment of temperature regimes provided by lasers with 0.81 and $0.97 \mu \mathrm{m}$ wavelengths showed that the stone surface temperature during fragmentation in the air reached 40 and $57^{\circ} \mathrm{C}$, respectively, and it was 25 and $33^{\circ} \mathrm{C}$ in liquid.

The obtained morphological and thermometric data suggest safety of lasers used for controlled fragmentation of potentially infected urinary calculi.

Conclusion. The use of continuous-wave diode lasers with strongly heated distal fiber tips at 0.81 and $0.97 \mu \mathrm{m}$ wavelengths makes it possible to successfully fragment potentially infected urinary stones into size-controlled fragments, which may become a significant factor in prevention of systemic inflammatory response in the postoperative period.

Key words: laser lithotripsy; hot spot method; diode lasers; urolithiasis; infected calculi.

\section{Introduction}

Infectious inflammatory complications occur after contact laser lithotripsy in nearly $27.4 \%$ of cases, according to different authors [1, 2]. The incidence of infected stones in sterile urine varies from 25 to $48 \%$ [35]. One of the triggers of infectious processes developing in the kidney is known to be calculus disintegration followed by the release of bacteria and their toxins from the biofilm [6]. To prevent complications, it is important to search for new mechanisms and methods of laser exposure providing calculi fragmentation without scattering of fragments and microbial dissemination into the pelvicalyceal system of the kidney.

For this purpose, our research team has developed a method for controlled coarse fragmentation of calculi using a strongly heated distal fiber tip (the "hot spot" method) with a light-absorbing coating of colloidal solution of graphite microparticles in silicone varnish [7]. Stone fragmentation effect was achieved through the high temperature of the distal fiber tip [8-10].

This paper presents a study of application safety of diode lasers with different wavelengths $(1.47,0.97$, and $0.81 \mu \mathrm{m}$ ) for lithotripsy based on the "hot spot" method

Corresponding author: Olga S. Streltsova, e-mail: strelzova_uro@ mail.ru 
providing a controlled change in the degree of stone destruction. The lasers under study differ in tissue penetration depth and, consequently, their thermal effect on the tissue. When using a light guide with a light-absorbing coating, the surrounding tissues absorb laser radiation, which inevitably leads to their topical heating [7].

To solve the problem of improving laser exposure modes and creating a safe medical technique for contact stone fragmentation, theoretical and experimental evaluation of heat transfer was carried out using model media and the ureteral tissue. The following physical factors were considered to be possible sources of injury during the procedure: 1) heating of ureteral tissues adjacent to the stone to injury threshold; 2) burning of the organic coating of the optical fiber on the calculus surface with plasma formed in burning reaction. The extent of adjacent tissue injury due to intraoperative errors was also evaluated: short-time contact with the ureteral wall as the result of the fiber slipping off the stone surface.

The aim of the study was to evaluate the possibilities of applying the technology of urinary calculi fragmentation by continuous-wave diode lasers at various wavelengths using fiber light guides with strongly heated distal tips for controlled fragmentation and minimization of traumatic effects on the adjacent tissues.

\section{Materials and Methods}

Postoperative ureteral tissues and model media were used as study objects. Fragmentation of urinary stones with cross-sectional dimensions of 5 to $29 \mathrm{~mm}$ was performed on postoperative samples $(n=58)$. X-ray density of the stones ranged from $119 \mathrm{HU}$ to $1735 \mathrm{HU}$, according to the Hounsfield scale.

Standard certified continuous-wave diode lasers with fiber output to similar quartz light guides were used in the study. The distal tip of the light guide with a diameter of $550 \mu \mathrm{m}$ was cleared from the protective coating by $3-5 \mathrm{~mm}$ length. Its end was coated with a layer of graphite microparticles in silicone varnish [7]. The output power of laser radiation was $10 \mathrm{~W}$. The stones and adjacent urinary tract tissues were exposed to laser radiation at wavelengths of $0.81(n=17), 0.97 \quad(n=22)$, and $1.47 \mu \mathrm{m}(\mathrm{n}=19)$. To form the groups, stones for fragmentation were selected at random.

The lasers under study had different absorption in water and in biological tissue: absorption coefficient at $0.81 \mu \mathrm{m}$ wavelength was $0.02 \mathrm{~cm}^{-1}$, at $0.97 \mu \mathrm{m}$ wavelength $-0.2 \mathrm{~cm}^{-1}$, at $1.47 \mu \mathrm{m}$ wavelength $20 \mathrm{~cm}^{-1}$ [11]. Since $80 \%$ of soft tissue consists of water, absorption coefficient for water and tissue was considered to be the same in the experiment.

Heating the urinary tract tissues adjacent to calculi during lithotripsy was studied using an oscilloscope equipped with a thermocouple. As a model medium, a ureter phantom (a silicone tube with $7 \mathrm{~mm}(22 \mathrm{Ch})$ diameter) was used at the first stage, at the second stage we used ureters taken from adult corpses during autopsy and dissected longitudinally.

In the first case, the stone was placed in the tube with its lower part plugged, the tube was filled with saline. A temperature sensor was placed at the contact area of the calculus and the inner surface of the tube. The heated tip of the light guide with radiation was applied to the calculus through the upper open end of the tube. The temperature was measured with a thermocouple at full thermal contact of the stone with the model medium walls.

In the second case, the calculus was placed upon the dissected ureteral tissue and was fragmented with the laser. Damage to the ureteral tissue was assessed by histological examination.

To simulate the intraoperative error (short contact with the ureteral wall as the result of the fiber slipping off the stone surface), the ureter mucosa was processed in a point-contact mode with the distal tip of the light guide heated by radiation to a high temperature for less than $1 \mathrm{~s}, 1$ and $2 \mathrm{~s}$ in the air. Condition of the ureteral tissue was assessed using histological sections stained with hematoxylin and eosin.

\section{Results}

A series of experiments on urinary stone fragmentation by lasers with wavelengths of $0.81 \mu \mathrm{m}$, 0.97 , and $1.47 \mu \mathrm{m}$ showed that exposure time required for calculus destruction does not depend on radiation wavelength, but it depends on the stone density, crosssectional dimension and ranges from 1 to $100 \mathrm{~s}$. On average, a stone was fragmented for 9-15 s.

Comparative analysis of stone fragmentation efficiency with different lasers showed that at $0.97 \mu \mathrm{m}$ wavelength, both in atmospheric air and in liquid, all the stones with X-ray density up to $1400 \mathrm{HU}(\mathrm{n}=20)$ were successfully fragmented, but it turned to be impossible to fragment 2 stones with $1735 \mathrm{HU}$ density in liquid.

When using a $0.81 \mu \mathrm{m}$ laser, all stones with 1000 to $1400 \mathrm{HU}$ density were fragmented $(n=10)$ in air, while fragmentation in liquid was successful only for stones with X-ray density under $1000 \mathrm{HU}(\mathrm{n}=5)$. Fragmentation of two stones with $1100 \mathrm{HU}$ and $1270 \mathrm{HU}$ density in liquid was no success.

Fragmentation of stones using a laser with $1.47 \mu \mathrm{m}$ wavelength was effective both in air $(n=9)$ and in liquid $(n=10)$. The maximum density of fragmented stones in this series of experiments was $1560 \mathrm{HU}$.

Experimental evaluation of temperature regimes in stone fragmentation at wavelengths under study. Figure 1 shows time dependences of calculi surface temperatures at different radiation wavelengths. Thermophysical parameters were determined based on water characteristics. In the experiment, we took into account the time required to reach the maximum temperature on the stone surface when placing a light 


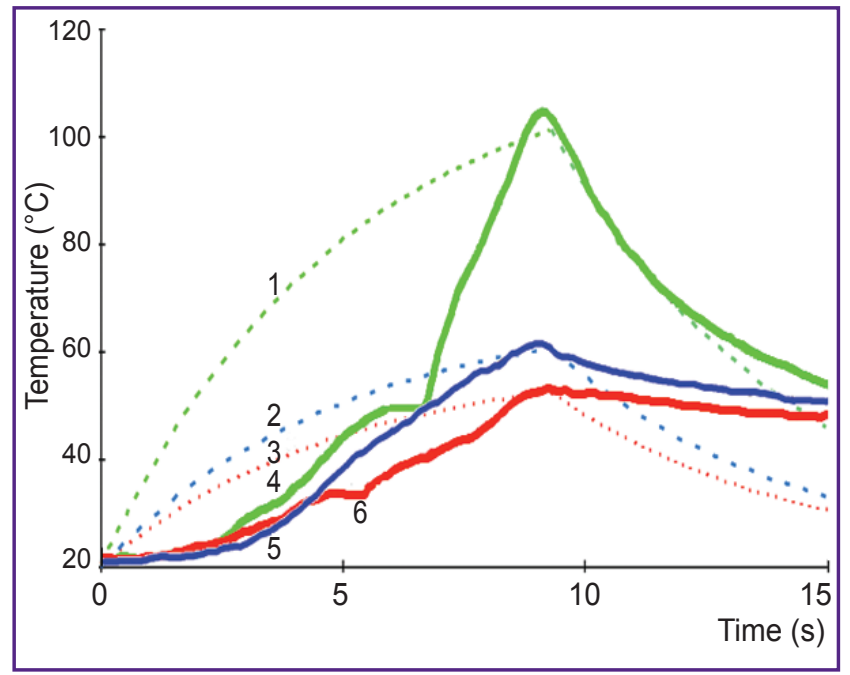

Figure 1. Diagrams of experimental evaluation of heating effect on the calculi by $10 \mathrm{~W}$ laser radiation at $1.47 \mu \mathrm{m}(1)$, $0.97 \mu \mathrm{m}$ (2), and $0.81 \mu \mathrm{m}(3)$ wavelengths for $9 \mathrm{~s}$

Temperature curve oscillograms: at $\lambda=1.47 \mu \mathrm{m}$ (4) heating to $80^{\circ} \mathrm{C}$ occurred; at $\lambda=0.97 \mu \mathrm{m}-$ to $57^{\circ} \mathrm{C}$ (5); at $\lambda=0.81 \mu \mathrm{m}$ (6) - to $42^{\circ} \mathrm{C}$. Initial temperature was $20^{\circ} \mathrm{C}$

guide with laser radiation at one spot - in the stone center.

Recording was performed when heating the stone during $9 \mathrm{~s}$, after which the laser was turned off, heating of the stone was stopped for 8-10 s.

The selected time parameters corresponded to the average values obtained when fragmenting the stone into two pieces in previous studies [8].

It follows from the given oscillograms that laser radiation heats the stone surface to $80^{\circ} \mathrm{C}$ at $\lambda=1.47 \mu \mathrm{m}$ during the established time (9 s), which is certainly amazing as it corresponds to photocoagulation effect for biotissues. A laser operating at $1.47 \mu \mathrm{m}$ wavelength was excluded from further investigation.

At 0.81 and $0.97 \mu \mathrm{m}$ wavelengths, laser radiation generates significantly lower temperature reaction on the stone surface making it possible to use such lasers for urinary stone fragmentation.

Laser impact on the ureteral tissue at 0.81 and $0.97 \mu \mathrm{m}$ wavelengths. When fragmenting the calculi by laser radiation at 0.81 and $0.97 \mu \mathrm{m}$ wavelengths in air, a temperature of 40 and $57^{\circ} \mathrm{C}$, respectively, was obtained on the stone surface in the area of contact with the ureteral mucosa. When fragmenting in liquid, the temperature was $25^{\circ} \mathrm{C}$ at $\lambda=0.81 \mu \mathrm{m}$ and $33^{\circ} \mathrm{C}$ at $\lambda=0.97 \mu \mathrm{m}$. Visual inspection of macro specimen mucosa in the area of contact with the stone revealed no pathological changes. Thus, it can be established that stone exposure duration up to $9 \mathrm{~s}$ with lasers at these wavelengths is unlikely to heat the entire calculus volume to injury threshold.

The "hot spot" method may be accompanied by burning of stone components with plasma formed in burning reaction. We proposed to solve this problem by suppressing the process of burning with an inert gas. To reduce burning of stone material and light guide tip, $\mathrm{CO}_{2}$ gas was supplied to the area of calculus contact with the light guide heated to $2000 \mathrm{~K}$ [7, 9]. In this study, urinary stone fragmentation was carried out ex vivo both in saline solution and in atmospheric air with direct contact of the heated fiber tip with the stone. It was found that at low rates of $\mathrm{CO}_{2}$ gas flow (about $(3-6) \cdot 10^{-3} \mathrm{~L} / \mathrm{min}$ ) through a 3-mm tube, no plasma occurred (Figure 2).

Morphological examination of the ureter. Thickness of mucosal, submucosal and muscular layers of the ureter was measured on a histological preparation (Figure $3(\mathrm{a})$ ). The urothelium thickness was $53.0 \pm 0.4 \mu \mathrm{m}$, subepithelial connective tissue structures of mucosal and submucosal layers were $417.0 \pm 19.0 \mu \mathrm{m}$ thick, muscular layer $-532.0 \pm 24.0 \mu \mathrm{m}$.

Figure 3 (b)-(e) shows images of histological preparations obtained when simulating the intraoperative situation - laser light guide slipping off the stone to the ureter wall.

Focal defects of the inner layers of the ureteral wall with different lengths and depths appeared depending on the time of laser exposure and the intensity of pressing the fiber against the ureteral mucosa. For example, when exposure with a $0.81 \mu \mathrm{m}$ laser light guide had minimum duration (contact for less than $1 \mathrm{~s}$ ), there could be detected surface defects of the mucosal epithelial layer with $80-100 \mu \mathrm{m}$ depth and length of up to $500 \mu \mathrm{m}$ with minimum coagulation changes in defect edges and bottoms, similar to erosion (Figure 3 (c)). When exposure time increased (pressing the $0.81 \mu \mathrm{m}$ laser light guide for $2 \mathrm{~s}$ ), there appeared defects of

Figure 2. Photo of a plasma torch in stone destruction by laser radiation at $0.81 \mu \mathrm{m}$ wavelength:

(a) without blowing over with $\mathrm{CO}_{2}$ gas; (b) blowing over with $\mathrm{CO}_{2}$ gas at a flow rate of $(3-6) \cdot 10^{-3} \mathrm{~L} / \mathrm{min}$
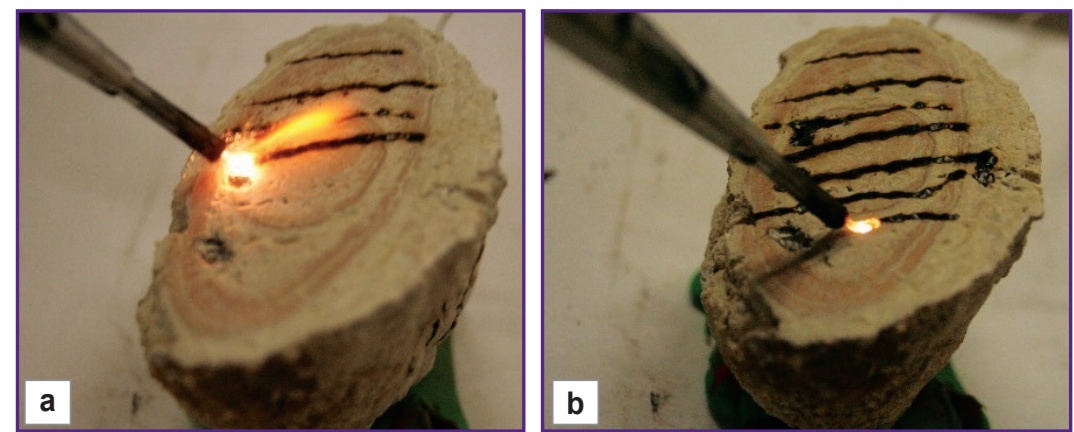


\section{CLINICAL SUPPLEMENTS}
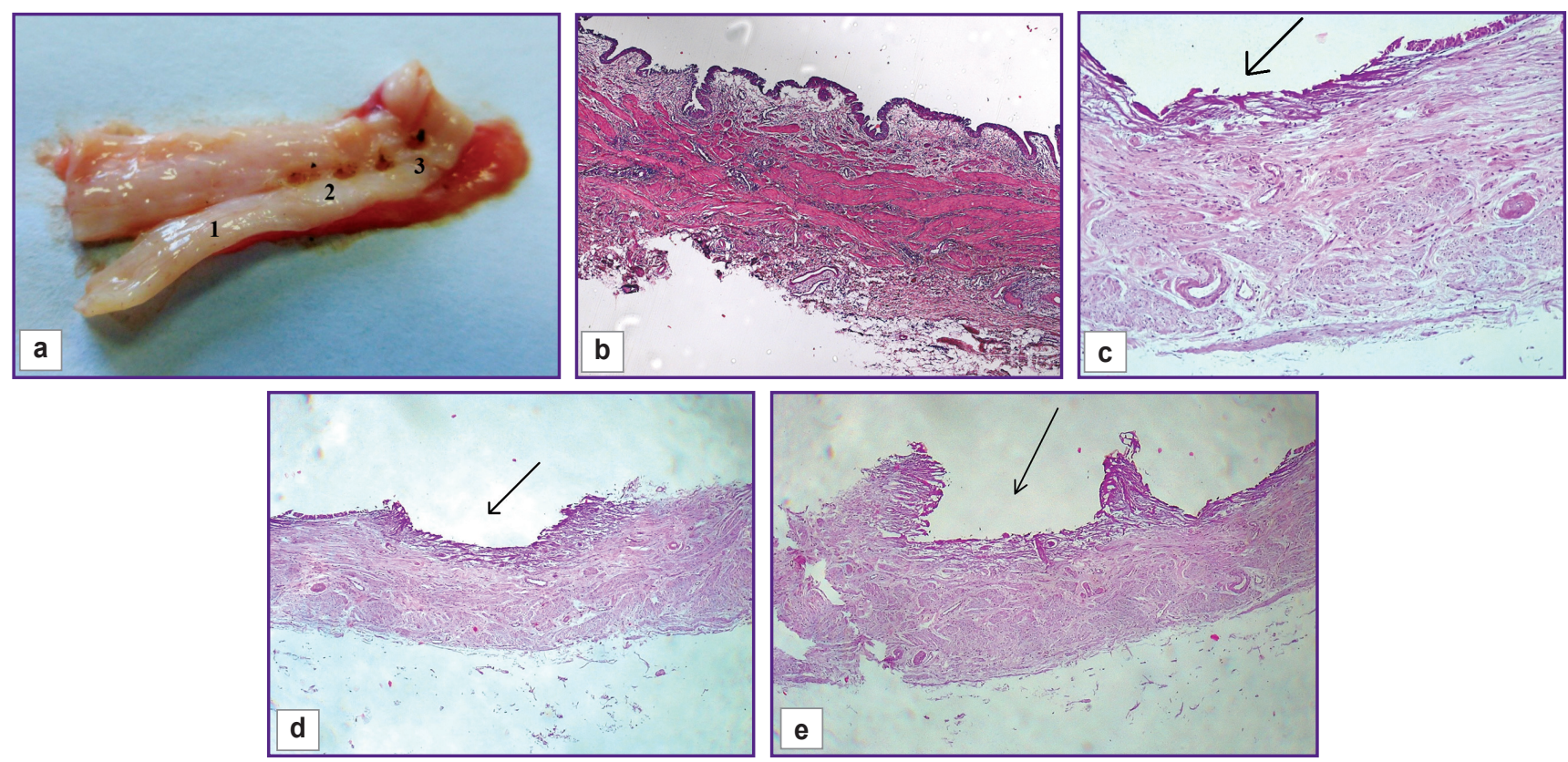

Figure 3. Images of the ureter obtained when simulating an intraoperative error - laser fiber slipping off the stone and coming into contact with the ureter (the contact area is shown by the arrow):

(a) macro specimen; the ureter after exposure to laser radiation: (1) contact for less than $1 \mathrm{~s}$ at $\lambda=0.81 \mu \mathrm{m}$; (2) pressing for $2 \mathrm{~s}$ at $\lambda=0.81 \mu \mathrm{m}$; (3) pressing for $2 \mathrm{~s}$ at $\lambda=0.97 \mu \mathrm{m}$; (b)-(e) histological specimens; hematoxylin and eosin staining; $x 100$ : (b) normal ureteral wall; (c) the ureteral wall after contact with the quartz fiber at $\lambda=0.81 \mu \mathrm{m}$ for less than $1 \mathrm{~s}$; (d) the ureteral wall after pressing the quartz fiber at $\lambda=0.81 \mu \mathrm{m}$ for $2 \mathrm{~s}$; (e) the ureteral wall after pressing the quartz fiber at $\lambda=0.97 \mu \mathrm{m}$ for $2 \mathrm{~s}$

$200 \times 800 \mu \mathrm{m}$ depth and $300 \times 1000 \mu \mathrm{m}$ length (see Figure $3(\mathrm{~d})$ ). When modeling a more significant damage (at $0.97 \mu \mathrm{m}$ wavelength during $2 \mathrm{~s}$ ), there appeared focal defects of the inner layers similar to acute ulcers with depths and lengths of $400 \times 1500$ and $400 \times 1200 \mu \mathrm{m}$, respectively, their bottoms being represented by a submucosal layer (Figure $3(\mathrm{e})$ ).

Coagulation changes in connective tissue fibers of defect bottoms such as $200-300 \mu \mathrm{m}$ thick bright pink masses without fibrous structure were spread almost over the entire thickness of the submucosal layer, sometimes even reaching the muscular layer.

\section{Discussion}

To date, the use of a holmium:yttrium-aluminumgarnet (Ho:YAG) laser is considered to be the most effective method of urinary stone fragmentation, which has become the gold standard as it allows fragmenting the stones of any mineralogical type [12, 13]. The underlying mechanism of this method is vaporization of water inside the stone resulting in uncontrolled formation of different-sized fragments (from very large to very small) [14] and their scattering over the renal collecting system due to steam pressure. This phenomenon promotes massive release of toxins and bacterial flora from stone biofilms. In recent years, the literature has provided comparative descriptions of two lithotripsy modes using Ho:YAG laser, one of which is aimed at creating stone dust (dusting method), the other is used for fragmentation into large fragments and their subsequent extraction with baskets (basketing) [15-17]. Each method has both advantages and disadvantages. Disadvantages include the possibility of residual stone fragments, backflow of toxins and dust getting into the excretory ducts of the renal collecting system, which can be a source of infectious and inflammatory changes for the patient in the postoperative period.

In this study, controlled stone fragmentation was achieved through the use of a continuous-wave diode laser due to stone surface carbonization effect and mechanical destruction of the stone with a high temperature at the quartz fiber tip. Moreover, the quartz fiber and absorbing coating of its distal tip were identical in all experiments at different wavelengths.

Evaluation of stone fragmentation efficiency in liquid and in atmospheric air shows that the "hot spot" method based on continuous-wave diode laser radiation can be successfully used to fragment porous and potentially infected stones. It has been found [18-19] that X-ray density characteristic of such stones is $1400 \mathrm{HU}$ for calcium phosphate, $480 \mathrm{HU}$ for uric acid stones, $1285 \pm 284 \mathrm{HU}$ for struvite stones, $757 \pm 114 \mathrm{HU}$ for cysteine calculi.

The study of heat transfer in the area of stone contact with the medium, performed on the ureter phantom and ex vivo ureter samples, demonstrates safety of continuous-wave diode lasers for the "hot spot" method. 
Morphological evaluation of the ureteral tissue in the area of direct contact with the fiber (simulation of intraoperative slipping of the light guide from the stone) also confirms this. Even a two-second contact of the light guide with the ureteral wall resulted in focal defects, but they were unlikely to reach the muscular layer.

Laser heating of the adjacent ureteral tissues during stone fragmentation at 0.81 and $0.97 \mu \mathrm{m}$ wavelengths for $9 \mathrm{~s}$ in liquid was significantly lower than biotissue coagulation temperatures.

The original solution of using $\mathrm{CO}_{2}$ gas eliminates the risk of burning of organic stone components and plasma formation in burning reaction. When blowing the fiber tip over with $\mathrm{CO}_{2}$ through a 3-mm tube at a flow rate of (3-6) $\cdot 10^{-3} \mathrm{~L} / \mathrm{min}$, there is no organic matter burning.

Thus, commercially available for any healthcare facility, continuous-wave diode lasers with 0.97 and $0.81 \mu \mathrm{m}$ wavelengths and the use of the "hot spot" method at the quartz fiber tip provide the possibility to perform controlled fragmentation of potentially infected urinary stones, thereby reducing intraoperative dissemination of bacteria and toxins from the stone biofilms.

\section{Conclusion}

Application of continuous-wave diode lasers with a quartz fiber tip at $0.81 \mu \mathrm{m}$ and $0.97 \mu \mathrm{m}$ wavelengths using the "hot spot" method provides the possibility to fragment urinary stones including those potentially infected into size-controlled fragments, which may become a significant factor in prevention of systemic inflammatory response in the postoperative period.

Study funding. This study was supported by the grant of the Russian Science Foundation No.14-1500840 ח.

Conflict of interests. The authors have no conflict of interests to disclose.

\section{References}

1. Koras O., Bozkurt I.H., Yonguc T., Degirmenci T., Arslan B., Gunlusoy B., Aydogdu O., Minareci S. Risk factors for postoperative infectious complications following percutaneous nephrolithotomy: a prospective clinical study. Urolithiasis 2015; 43(1): 55-60, https://doi.org/10.1007/ s00240-014-0730-8.

2. Yang T., Liu S., Hu J., Wang L., Jiang $H$. The evaluation of risk factors for postoperative infectious complications after percutaneous nephrolithotomy. Biomed Res Int 2017; 2017: 4832051, https://doi.org/10.1155/2017/4832051.

3. Margel D., Ehrlich Y., Brown N., Lask D., Livne P.M., Lifshitz D.A. Clinical implication of routine stone culture in percutaneous nephrolithotomy - a prospective study. Urology 2006; 67(1): 26-29, https://doi.org/10.1016/j. urology.2005.08.008.

4. Palagin I.S., Sukhorukova M.V., Dekhnich A.V., Edelstein M.V., Shevelev A.N., Grinyov A.V., Perepanova T.S., Kozlov R.S., Kogan M.I. Current state of antibiotic resistance of pathogens causing community-acquired urinary tract infections in Russia: "DARMIS" study (2010-2011). Klinicheskaya mikrobiologiya i antimikrobnaya khimioterapiya 2012; 14(4): 280-302.

5. Korets R., Graversen J.A., Kates M., Mues A.C., Gupta M. Post-percutaneous nephrolithotomy systemic inflammatory response: a prospective analysis of preoperative urine, renal pelvic urine and stone cultures. J Urol 2011; 186(5): 1899-1903, https://doi.org/10.1016/j.juro.2011.06.064.

6. Didenko L.V., Tolordava E.R., Perpanova T.S., Shevlyagina N.V., Borovaya T.G., Romanova Yu.M., Cazzaniga M., Curia R., Milani M., Savoia C., Tatti F. Electron microscopy investigation of urine stones suggests how to prevent post-operation septic complications in nephrolithiasis. J Appl Med Sci 2014; 3(4): 19-34.

7. Bredikhin V.I., Bityurin N.M., Kamenskiy V.A., Smirnova L.A., Salomatina E.V., Strel'tsova O.S., Pochtin D.P. Method of contact lithotripsy. Patent RU 2604800. 2015.

8. Streltsova O.S., Grebenkin E.V., Pochtin D.P., Bredikhin V.I., Kamensky V.A. Contact laser lithotripsy using strongly heated distal tip of optic fiber. Sovremennye tehnologii v medicine 2017; 9(4): 137-142, https://doi.org/10.17691/ stm2017.9.4.17.

9. Sapogova N., Bredikhin V., Bityurin N., Kamensky V., Zhigarcov V., Yusupov V. Model for indirect laser surgery. Biomed Opt Express 2016; 8(1): 104-111, https://doi. org/10.1364/boe.8.000104.

10. Bredikhin V., Kamensky V., Sapogova N., Elagin V., Shakhova M., Snopova L., Bityurin N. Indirect laser surgery. Applied Physics A 2016; 122(3): 181, https://doi.org/10.1007/ s00339-016-9734-2.

11. Boulnois J.L. Photophysical processes in recent medical laser developments: a review. Lasers in Medical Science 1986; 1(1): 47-66, https://doi.org/10.1007/bf02030737.

12. Leijte J.A., Oddens J.R., Lock T.M. Holmium laser lithotripsy for ureteral calculi: predictive factors for complications and success. J Endourol 2008; 22(2): 257-260, https://doi.org/10.1089/end.2007.0299.

13. Pierre S., Preminger G.M. Holmium laser for stone management. World J Urol 2007; 25(3): 235-239, https://doi. org/10.1007/s00345-007-0162-y.

14. Teichman J.M., Vassar G.J., Bishoff J.T., Bellman G.C. Holmium:YAG lithotripsy yields smaller fragments than lithoclast, pulsed dye laser or electrohydraulic lithotripsy. J Urol 1998; 159(1): 17-23, https://doi.org/10.1016/s00225347(01)63998-3.

15. Patel A.P., Knudsen B.E. Optimizing use of the holmium: YAG laser for surgical management of urinary lithiasis. Curr Urol Rep 2014; 15(4): 397, https://doi.org/10, 1007/s11934-0140397-2.

16. Santiago J.E., Hollander A.B., Soni S.D., Link R.E., Mayer W.A. To dust or not to dust. a systematic review of ureteroscopic laser lithotripsy techniques. Curr Urol Rep 2017; 18(4): 32, https://doi.org/10.1007/s11934-017-0677-8.

17. Weiss B., Shah O Evaluation of dusting versus basketing - can new technologies improve stone-free rates? Nat Rev Urol 2016; 13(12): 726-733, https:/ldol,org/10.1038/ nrurol.2016.172.

18. Turk C., Knoll T, Petrik A., Sarica K., Seitz C., Straub M. Guidelines on urolithiasis. European Association of Urology; 2011.

19. Kuwahara M., Kageyama S., Kurosu S., Orikasa S. Computed tomography and composition of renal calculi. Urol Res 1984; 12(2): 111-113, https://doi.org/10.1007/bf00257175. 